\title{
Grand Challenges in Acoustic Remote Sensing: Discoveries to Support a Better Understanding of Our Changing Planet
}

\author{
Bryan C. Pijanowski ${ }^{1 \dagger}$ and Craig J. Brown ${ }^{2 \star t}$ \\ ${ }^{1}$ Department of Forestry and Natural Resources, Purdue University, West Lafayette, IN, United States, ${ }^{2}$ Department of \\ Oceanography, Dalhousie University, Halifax, NS, Canada
}

Keywords: acoustics, sound, sonar, soundscapes, sensors, transducers

\section{INTRODUCTION}

There are numerous 21 st century environmental grand challenges that need to be addressed by the scientific community. Several that have been identified are even considered to threaten life on Earth (Turner et al., 1990; Pimm et al., 1995; Costanza et al., 1998; Kates et al., 2001; Koh et al., 2004; Orr et al., 2005; Rockström et al., 2009; Foley et al., 2011; Wu, 2013). Environmental grand challenges that need critical research include understanding how the environment is changing due to the global footprint of human activities, such as climate change, habitat alteration or modifications to the animal community, all of which are occurring at unprecedented rates.

Scientists and engineers need to rise to address these challenges by advancing the field of remote sensing. One of the promising remote sensing technologies include those that utilize acoustics - either active or passive - which can uniquely characterize the structure and dynamics of terrestrial and aquatic systems. Acoustic remote sensing has advanced rapidly in recent years as researchers have drawn upon several well-known measuring technologies including the applications of transducers that measure sound in air, water and in solids, applying and advancing a variety of signal processing techniques, and leveraging generic data mining technologies that facilitate the analysis of acoustic data. Ultimately, research in remote sensing aims to discover patterns in data that can be used to understand how the Earth system is changing, acoustics being one form of data that is becoming increasingly useful. We need a forum for scholars across a variety of fields to communicate their discoveries in order to improve the well-being of people and other life on Earth.

Here, we outline the kinds of applications of acoustic remote sensing that we hope will appear in the Acoustics Specialty Section of Frontiers in Remote Sensing (FRS). As co-Chief Editors for this specialty section, we want to convey our excitement about this emerging field of acoustic remote sensing and the promise that these technologies can provide scholars to advancing the greatly needed discoveries of our rapidly changing planet.

Received: 29 November 2021

Accepted: 01 December 2021

Published: 06 January 2022

Citation:

Pijanowski BC and Brown CJ (2022)

Grand Challenges in Acoustic Remote

Sensing: Discoveries to Support a

Better Understanding of Our

Changing Planet.

Front. Remote Sens. 2:824848.

doi: 10.3389/frsen.2021.824848

\section{ACTIVE ACOUSTIC REMOTE SENSING}

Mapping the surface of the earth using satellite (or airborne) remote sensing techniques have revolutionized our understanding of earth, ocean and atmospheric systems over the past 5 decades (Dubovik et al., 2021). Most of these sensors use information from the electromagnetic (EM) spectrum to measure and monitor the earth. These technologies have allowed terrestrial systems and the surface of the ocean to be repeatedly mapped at high resolution, with some sensors now capable of mapping at sub-meter resolution (Hansen and Loveland, 2012; Mulla, 2013; Almeida et al., 2019). 

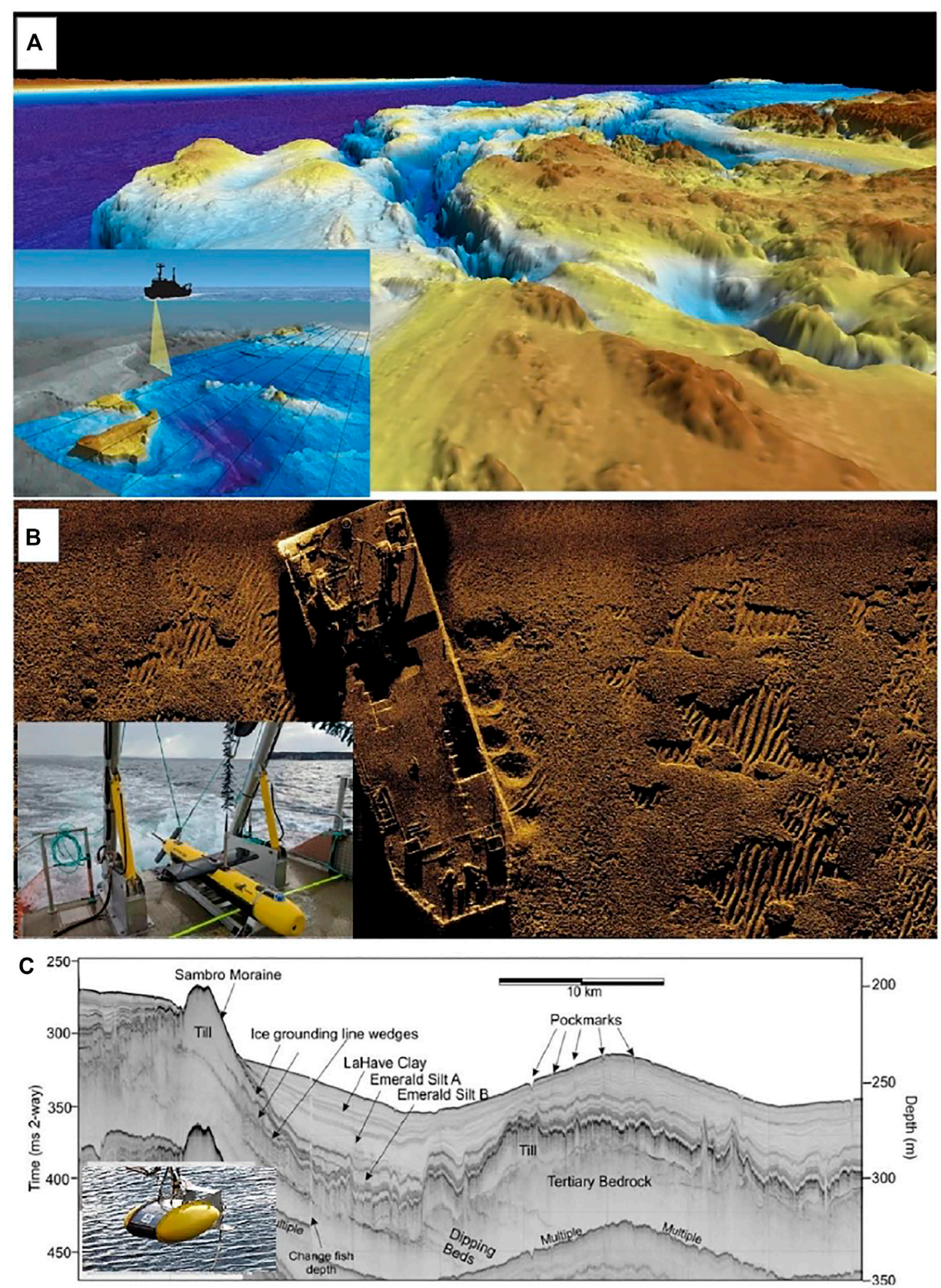

FIGURE 1 | Examples of active acoustic remote sensing data sets and sensors. (A) Multibeam echosounder bathymetry showing a 3D view of a digital elevation model of the seafloor derived from multibeam bathymetric measurements. Inset image shows how MBES data sets are collected. Imagery courtesy of the Dalhousie University, Seascape Ecology and Mapping Lab (www.seafloormapping.ca); (B) Synthetic Aperture Sonra data set showing a ship wreck and seafloor sediment bedforms. Data is $3 \mathrm{~cm}$ horizontal resolution and collected from a towed SAS system shown inset (Kraken Robotics Katfish). Imagery courtesy of Kraken Robotics (https://krakenrobotics.com/); (C) Sub-bottom profiler data showing sediment stratigraphy beneath the seafloor. The profile was collected using a towed sensor platform (Geoforce DTS). Imagery courtesy of Geoforce Group Ltd. (https://www.geoforcegroup.com/). 
However, electromagnetic waves do not penetrate very far through water, and with $70 \%$ of the earth covered by the oceans with an average depth of $3.6 \mathrm{~km}$, the vast majority of the globe remains extremely poorly mapped. For example, it is estimated that only $18 \%$ of the seabed is mapped at a comparable resolution to that of terrestrial environments (Mayer et al., 2018).

Active acoustic remote sensing methods generate a sound pulse and measure the returning signal (echo) to deduce information about the sensed environment. These active systems have filled this sensor void in helping us understand underwater systems where EM sensors have difficulty reaching. Sonar (Sound Navigation and Ranging) systems primarily utilize frequencies ranging from $1 \mathrm{kHz}$ to several hundreds of $\mathrm{kHz}$ (Lurton, 2010), and the design and engineering of these sensors has advanced and diversified for use in a wide range of application: Singlebeam echosounders (SBES) and multibeam echosounders (MBES) are used to map seafloor bathymetry for nautical charting (e.g., Mayer, 2006; Lurton, 2010; Brown et al., 2011; Mayer et al., 2018); MBES, sidescan sonar (SSS) and lower frequency sub bottom profilers (SBP) are used to study the morphology and geology of the seabed (e.g., Piper et al., 1999; Polyak et al., 2001; Collier and Brown, 2005; Wilson et al., 2007; Lecours et al., 2016); SBES, MBES and acoustic telemetry are used for fisheries applications to map fish biomass and movement (e.g., Mayer, 2002; Foote, 2009; Colbo et al., 2014; Crossin et al., 2017; Muñoz et al., 2020) or to map benthic ecosystems (e.g., Brown et al., 2011; Micallef et al., 2012; Ierodiaconou et al., 2018; Lacharite et al., 2018; Brown et al., 2019; Wilson et al., 2021); Synthetic aperture sonars (SAS) are primarily used for defense applications (e.g., Hayes and Gough, 2009; Myers and Fawcett, 2010) with other applications such as benthic habitat or substrate mapping recently emerging (Brandes and Ballard, 2019; Thorsnes et al., 2019); Acoustic Doppler Current Profilers (ADCP) are used to investigate physical oceanographic phenomena including current speed, direction and transport of biological or geological particles (e.g., Fielding et al., 2004; Gartner, 2004; Thomson et al., 2012). At lower frequencies $(<1,000 \mathrm{~Hz})$, seismic systems have been developed for remote characterization of the deep seafloor subsurface (e.g., McConnell et al., 2012) and the physical structure of the overlying oceans (e.g., Ruddick et al., 2009). Examples of some of these types of sensors and data are shown in Figure 1. Although active acoustic remote sensing is dominated by uses in the underwater domain, there are also some terrestrial (e.g., terrestrial seismic exploration) and atmospheric applications (e.g., Sonic Detection and Ranging (SODAR) and Radio Acoustic Sounding Systems (RASS) (Bradley, 2007)).

\section{PASSIVE ACOUSTIC REMOTE SENSING}

Passive acoustic technologies focus primarily on measuring sound and/or vibrations in air, water and/or solids. These passive technologies focus on three important spectral ranges those in the human audible range $(20-20,000 \mathrm{~Hz})$, above human hearing $(>20,000 \mathrm{~Hz})$ or ultrasonic, and those below human hearing sensitivity (less than $20 \mathrm{~Hz}$ ), or infrasonic. Sound sources in these ranges include sounds from biological organisms (animals that are communicating using sound), geophysical dynamics (thunder, sounds from rain, and earthquakes), and sounds from human-made objects (sirens, road noise). Together these occur as soundscapes (Schafer, 1993; Kang, 2006; Pijanowski et al., 2011a; Pijanowski et al., 2011b). Studies of soundscape ecology are at the forefront of ecological sciences as it focusses on the interplay of landscape/ seascape dynamics and spatial-temporal acoustical patterns (Fuller et al., 2015; Doser et al., 2020; Lin et al., 2021). As terrestrial and aquatic acoustic sensors (Figure 2) have now become relatively affordable and analytical tools such as Seewave (Sueur et al., 2008), AP.exe (Towsey et al., 2014), and SoundEcologyR (Villanueva-Rivera et al., 2018) have been developed, work in passive acoustic monitoring has flourished. Advances in terrestrial, marine, freshwater, and urban soundscape ecology has exploded in recent years; and, due to the robustness of current sensors, research has now extended across tropical, temperate, arid, and cold climates and in freshwater and marine systems.

\section{GRAND CHALLENGES}

Although some areas of acoustic remote sensing are relatively mature and have established journals for publication, many of the emerging techniques and technologies, novel applications, and data interpretation and analyses methods have no clear venue for publication. It is our hope that FRS may offer this very young science a forum for which we can share our discoveries.

We seek to have acoustic remote sensing scholars from all over the world (e.g., Pijanowski et al. (2021) for a summary of the exceptional work being done in Latin America for example) publish in FRS in the following areas:

Advances in transducer technologies Sonar design have diversified tremendously in the past $2-3$ decades, with a move from analogue to digital systems, and improvements in performance, resolution, and positioning. Swath sonar systems (e.g., MBES, SSS, SAS) continue to advance, with increasing resolution and capability to operate over a range of frequencies (e.g., multispectral MBES - Gaida et al., 2018; Brown et al., 2019; Misiuk et al., 2020). Microphones for passive acoustics can come in a variety of configurations, from single transducers to those arranged in arrays (e.g., double M/S). New configurations can provide more detailed information about the location of sound sources, how sound propagates through media, and the extent that sound can reach a receiver. Power is also a challenge with field sensors so technological solutions are needed to ensure that sensors can collect data for longer periods or time or in environments (e.g., cold) where battery power is limiting. Papers in FRS should advance the technology frontier in transducer technologies that can lead to more discoveries in our sonic world.

Advances in acoustic sensor networks. How can researchers create wired or wireless acoustic sensor networks that support the coordination of data collection, data transfers and onboard sensor 

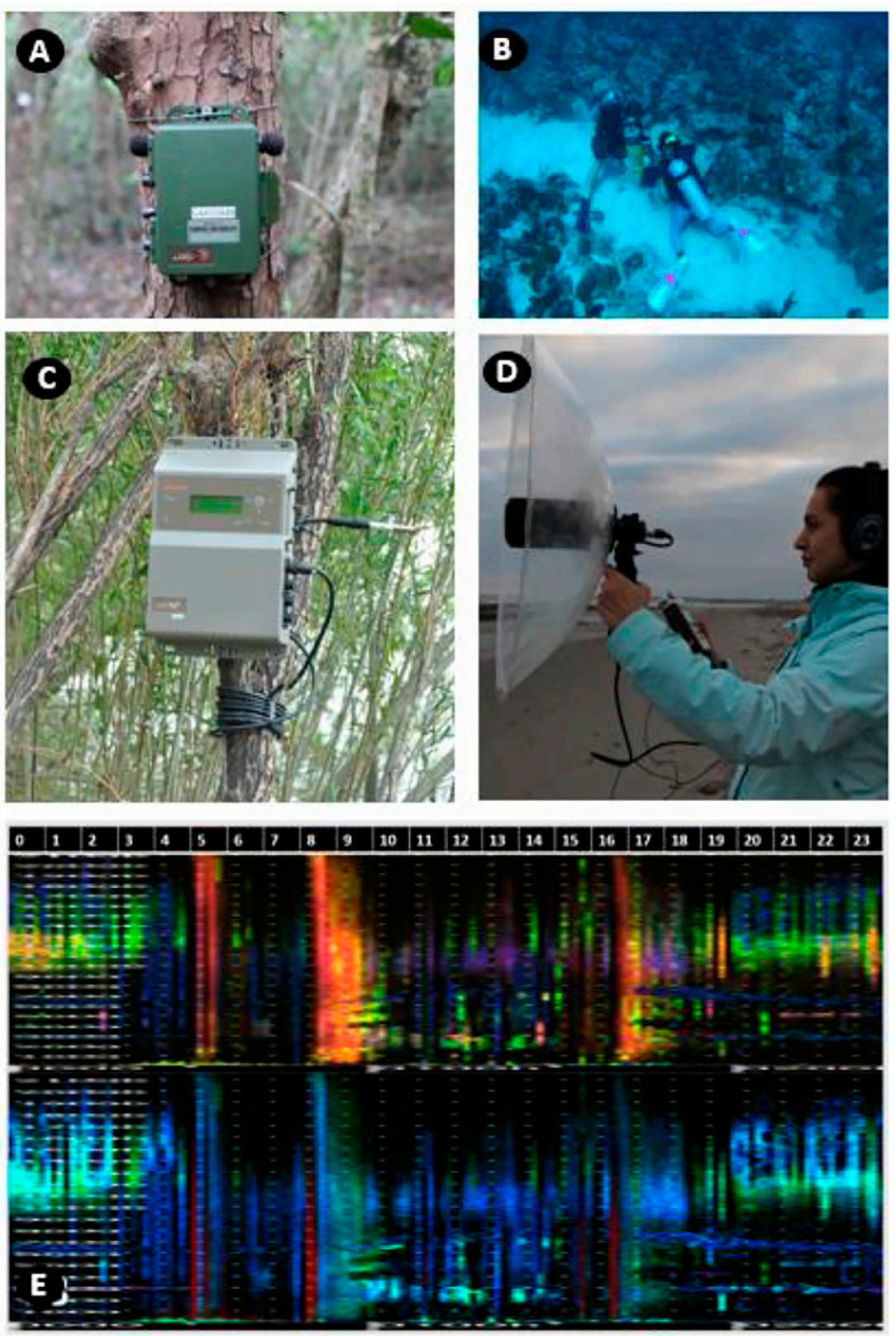

FIGURE 2 Passive acoustics technologies that show (A) a terrestrial passive acoustic recorder mounted to a tree in the Sundarbans, Bangladesh (photo credit B. Pijanowski), (B) a hydrophone being deployed in a Weinberg Reef, Puerto Rico (photo credits Jack Olson, Rebecca Becicka and Alex Veglia), (C), an ultrasonic (bat) recorder along the Tuul River, Mongolia (photo credit, B. Pijanowski), (D) a hand-held parabolic dish mounted on a hypercardioid microphone (photo credit, B. Pijanowski and M. Ghadiri) and (E) a false color spectrogram of 24 1-h recordings made in Feb, 2017 in Issa Valley, Tanzania (courtesy of Francesco Rivas Fuenzalida).

capabilities such as edge computing? How can these acoustic sensors be integrated with other environmental sensors, such as those that collect data on weather, imagery, and chemistry? Large-scale acoustic sensor networks have been challenging to deploy and maintain (e.g., Akyildiz et al., 2005) but advances continue to occur moving us toward implementing these are very large spatial extents (e.g., Erbe et al., 2015; Roe et al., 2021; Sherrit et al., 2021).

Advances with sensor platforms Deploying sonars on autonomous platforms such as autonomous surface vehicles
(ASVs) or autonomous underwater vehicles (AUVs) (Grasmueck et al., 2006; Wynn et al., 2014) is providing significant reduction in the cost of data acquisition. Platform design, capabilities and sensor integration is an emerging field, with rapid innovation taking place which will continue to drive the field of acoustic remote sensing forward. We are interested in articles that describe new acoustic sensor platforms for any environmental application (e.g., Lammers et al., 2008; Aide et al., 2013; Sousa-Lima et al., 2013; Potamitis et al. 2014; Wynn et al., 2014; Hill et al., 2018; Diviacco et al., 2021). 
Advances in labeling and retrieval of acoustic data Many researchers are now collecting acoustic data that is difficult to manage due to the size and complexity of the information stored. Advances in information retrieval systems are needed so that researchers can query their large databases for use in their research. Acoustic information retrieval systems will require innovative approaches as many current databases lack the ability to readily store acoustic data. Soundscape information retrieval systems is at the forefront of engineering work to support acoustic research (Bellisario and Pijanowski, 2019; Lin and Tsao, 2020; Mooney et al., 2020).

Advances in acoustic sensor applications (both active and passive) How can our acoustic sensors be used to better understand patterns of biodiversity, map and study aquatic ecosystems, measure the impact of noise on animal communication (e.g., Patricelli and Blickley, 2006; Warren et al., 2006; McKenna et al., 2012; Duarte et al., 2021), understand patterns of environmental sounds like those from storms, such as wind, rain, thunder (e.g., Bedoya et al., 2017), earthquakes (Wu et al., 2020), and the vibroscapes of animals such as spiders (e.g., Virant-Doberlet et al., 2019)? What new acoustic indices can be developed that assess changes in the environment (e.g., Gasc et al., 2013a; Gasc et al., 2013b; Pieretti and Farina, 2013; Fairbrass et al., 2017; Buxton et al., 2018; Deichmann et al., 2018; Bradfer-Lawrence et al., 2019; Burivalova et al., 2019)? How can acoustic remote sensing help us to understand and pose solutions to grand environmental problems such as climate change, habitat alteration, the decline of species at local to global scales, the impact of pollutants on ecosystem dynamics, and the introduction of non-native species into the environment?

Advances in big data acoustic mining and data processing Passive acoustic monitoring has solved many problems related to the recording of sound in harsh environments, but doing so means that there is now a tremendous amount of data to analyze, and many argue (e.g., Servick, 2014) that this has brought ecologists into the big data era. Similarly, active acoustic data acquisition is acquiring vast volumes of data, with a need to explore how to analyze, process and interpret these data source through integration of in situ validation measurements. With that transition, ecologists and data scientists are now applying a multitude of data mining tools to the analysis of massive acoustic data. These include those that classify sounds (e.g., Zhao et al., 2017), sort sounds through clustering algorithms (e.g., Bellisario et al., 2019a; Bellisario et al., $2019 b$ ), reduce the massive number of acoustic features that are calculated per recording in order to reduce the multidimensionality for more efficient and less complex analysis (Dias et al., 2021; Hilasaca et al., 2021), use of acoustic recordings that are integrated with human perception data (e.g., Aletta et al., 2016) and the development and application of advanced visualization tools such as false color spectrograms (Figure 2). Software development that supports the collection, modification, analysis, fusion, and visualization of acoustic data is needed to advance acoustic remote sensing research. In addition, data formats for sound files, traditionally stored as lossless formats such as wav and flac or as lossy formats such as $\mathrm{mp} 3$, could be improved to reduce costs to store data or reduce time to discovery.
Advances in seascape ecology The application of sonar for mapping the benthic environment (both marine and freshwater) has resulting in exponential growth in publications in this research area over the past 2 decades. Swath acoustic systems (MBES, SSS) coupled with geological and biological ground validation are now used to map underwater landscapes (benthoscapes - the seafloor component of seascapes (Brown et al., 2012; Pittman, 2017; Lacharite et al., 2018; Pittman et al., 2021; Wilson et al., 2021) in a comparable way that terrestrial landscapes are mapped using satellite remote sensing data sets on land. Physical oceanographic variables, sometime measured with acoustic remote sensing methods (e.g., water column data from MBES or ADCPs), or other forms/ sources of environmental data are increasingly being integrated with benthic data - offering new insights in understanding habitat use by marine organism, or species range shifts resulting from climate change. In addition, passive acoustic sensing in oceans (e.g., Gottesman et al., 2020, Gottesman et al., 2021) and freshwater systems such as ponds, lakes and rivers (e.g., Rountree and Juanes, 2017; Desjonquères et al., 2020; Gottesman et al., 2020; Linke et al., 2020; Rountree et al., 2020; Rountree and Juanes, 2020) is advancing at rapid paces too, providing us with rich information about how our aquatic systems are changing. With increasing data availability, this research area is primed for further growth in the coming decades.

Advances in understanding of landscape/seascapesoundscape relationships Sound produced by objects in terrestrial and aquatic environments is a spatially explicit phenomenon. Soundscape ecologists have focused a lot of research on understanding the relationship between patterns and processes occurring in landscapes and the composition and dynamics of the soundscape (Pekin et al., 2012; Fuller et al., 2015). Advances are needed in this area of research as it helps researchers and natural resource managers understand how human and organismal activities create the types of sounds that occur across space and time. Analyses of the interplay of landscapes/seascapes and soundscapes is at the forefront of many applications of acoustic remote sensing and FRS is especially interested in advancing this area of research. This research could also involve the integration of acoustic remote sensing data with that from other remote sensing platforms, such as those from LiDAR (e.g., Asner et al., 2012), hyperspectral (e.g., Asner and Martin, 2009) and multispectral imagery (e.g., Roy et al., 2021; Yan and Roy, 2021).

\section{GROWTH IN THIS RESEARCH FIELD}

Growth and expansion in this field of research has been enormous over the past 2 decades, mostly driven by improvements, innovations, and access to sensing technology. Figure 3 demonstrates this growth, through a basic search of the literature using the key words "Acoustic Remote Sensing" or "Active Acoustic Sensing" or "Passive Acoustic Sensing" in Web of Science, resulting in 2,650 publications. We acknowledge that this is likely a significant underestimate of the number of publications in this field, as many will have no standard key words. Nonetheless, it demonstrates the growth in this field over the past few decades. 

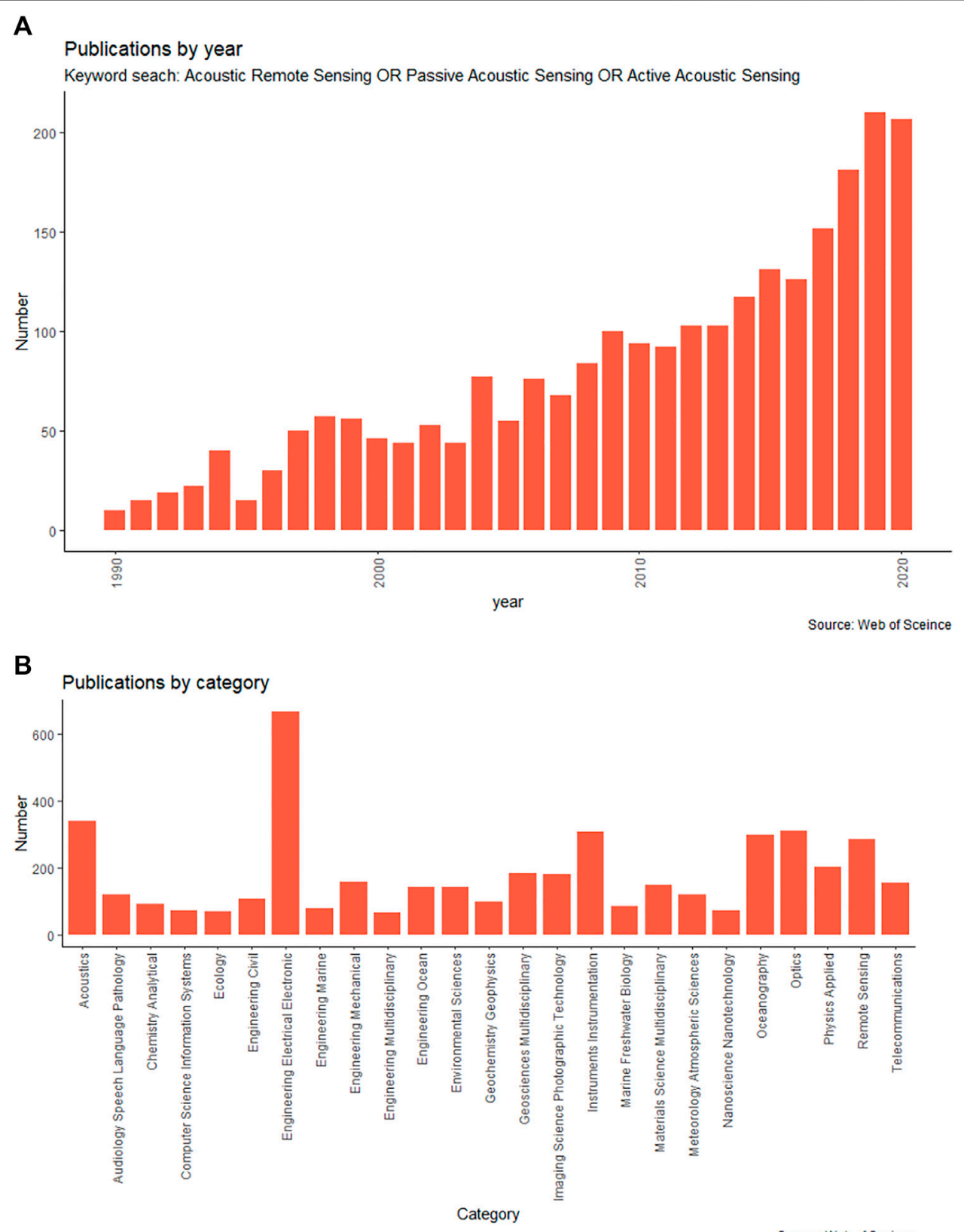

FIGURE 3 | Growth of the acoustic remote sensing field. (A): Web of Science search showing number of publications by year using the key words "acoustic remote sensing" or "active acoustic sensing" or "passive acoustic sensing"; (B): Number of publications by Web of Science Categories, highlighting the key areas where acoustic remote sensing research is applied (top 25 categories).

\section{CONCLUSION}

The sensor technologies and methodological advances that are outlined above have led to the emergence, expansion, and rapid growth of acoustic remote sensing research. Over the coming decades we anticipate that acoustic remote sensing will help improve our understanding of how the environment is changing due to human activities, such as climate change, habitat alteration and loss of biodiversity. Important global initiatives, such as Seabed
2030 (https://seabed2030.org/), will apply acoustic remote sensing to help map the ocean floor in higher resolution, the most poorly studied ecosystem on earth. Technological innovation will continue to improve sensors, and deployment automation will improve the way that these sensors are deployed into the environment, leading to new discoveries, and a better understanding of global environments. Often cutting across multiple disciplines and integrating diverse forms of data, research conducted in this field is often difficult to place in existing journals. FRS will therefore 
provide a much-needed forum for publishing science in this relatively young and exciting field of research.

\section{AUTHOR CONTRIBUTIONS}

All authors listed have made a substantial, direct, and intellectual contribution to the work and approved it for publication.

\section{REFERENCES}

Aide, T. M., Corrada-Bravo, C., Campos-Cerqueira, M., Milan, C., Vega, G., and Alvarez, R. (2013). Real-time Bioacoustics Monitoring and Automated Species Identification. PeerJ 1, e103. doi:10.7717/peerj.103

Akyildiz, I. F., Pompili, D., and Melodia, T. (2005). Underwater Acoustic Sensor Networks: Research Challenges. Ad Hoc Networks 3 (3), 257-279. doi:10.1016/ j.adhoc.2005.01.004

Aletta, F., Kang, J., and Axelsson, O. (2016). Soundscape Descriptors and a Conceptual Framework for Developing Predictive Soundscape Models. Landscape Urban Plann. 149, 65-74. doi:10.1016/j.landurbplan.2016.02.001

Almeida, L., Almar, R., Bergsma, E., Berthier, E., Baptista, P., Garel, E., et al. (2019). Deriving High Spatial-Resolution Coastal Topography from Submeter Satellite Stereo Imagery. Remote Sensing 11 (5), 590. doi:10.3390/ rs11050590

Asner, G. P., and Martin, R. E. (2009). Airborne Spectranomics: Mapping Canopy Chemical and Taxonomic Diversity in Tropical Forests. Front. Ecol. Environ. 7 (5), 269-276. doi:10.1890/070152

Asner, G. P., Mascaro, J., Muller-Landau, H. C., Vieilledent, G., Vaudry, R., Rasamoelina, M., et al. (2012). A Universal Airborne LiDAR Approach for Tropical forest Carbon Mapping. Oecologia 168 (4), 1147-1160. doi:10.1007/ s00442-011-2165-z

Bedoya, C., Isaza, C., Daza, J. M., and López, J. D. (2017). Automatic Identification of Rainfall in Acoustic Recordings, 75, 95-100. doi:10.1016/j.ecolind.2016.12.018

Bellisario, K. M., and Pijanowski, B. C. (2019). Contributions of MIR to Soundscape Ecology. Part I: Potential Methodological Synergies. Ecol. Indicators 51, 96-102. doi:10.1016/j.ecoinf.2019.02.009

Bellisario, K. M., VanSchaik, J., Zhao, Z., Gasc, A., Omrani, H., and Pijanowski, B. C. (2019a). Contributions of MIR to Soundscape Ecology. Part 2: Spectral Timbral Analysis for Discriminating Soundscape Components. Ecol. Inform. 51, 1-14. doi:10.1016/j.ecoinf.2019.01.008

Bellisario, K. M., Broadhead, T., Savage, D., Zhao, Z., Omrani, H., Zhang, S., et al. (2019b). Contributions of MIR to Soundscape Ecology. Part 3: Tagging and Classifying Audio Features Using a Multi-Labeling K-Nearest Neighbor Approach. Ecol. Inform. 51, 103-111. doi:10.1016/j.ecoinf.2019.02.010

Bradfer-Lawrence, T., Gardner, N., Bunnefeld, L., Bunnefeld, N., Willis, S., and Dent, D. (2019). Guidelines for the Use of Acoustic Indices in Environmental Research. Methods Ecol. Evol. 10 (10), 1796-1807. doi:10.1111/2041210X.13254

Bradley, S. (2007). Atmospheric Acoustic Remote Sensing: Principles and Applications. Boca Ratton: CRC Press.

Brandes, T. S., and Ballard, B. (2019). Adaptive Seabed Characterization with Hierarchical Bayesian Modeling of SAS Imagery. IEEE Trans. Geosci. Remote Sensing 57 (3), 1278-1290. doi:10.1109/TGRS.2018.2865606

Brown, C. J., Smith, S. J., Lawton, P., and Anderson, J. T. (2011). Benthic Habitat Mapping: A Review of Progress towards Improved Understanding of the Spatial Ecology of the Seafloor Using Acoustic Techniques. Estuarine Coastal Shelf Sci. 92 (3), 502-520. doi:10.1016/j.ecss.2011.02.007

Brown, C. J., Sameoto, J. A., and Smith, S. J. (2012). Multiple Methods, Maps, and Management Applications: Purpose Made Seafloor Maps in Support of Ocean Management. J. Sea Res. 72, 1-13. doi:10.1016/j.seares.2012.04.009

Brown, C., Beaudoin, J., Brissette, M., and Gazzola, V. (2019). Multispectral Multibeam Echo Sounder Backscatter as a Tool for Improved Seafloor Characterization. Geosciences 9 (3), 126. doi:10.3390/geosciences 9030126

Burivalova, Z., Game, E. T., and Butler, R. A. (2019). The Sound of a Tropical forest. Science 363 (6422), 28-29. doi:10.1126/science.aav1902

\section{ACKNOWLEDGMENTS}

The authors would like to thank Kraken Robotics (https:// krakenrobotics.com/), the Geoforce Group Ltd. (https://www. geoforcegroup.com/), and Vicki Gazzola from the Seascape Ecology and Mapping Lab at Dalhousie University for provision of imagery used in Figure 1.

Buxton, R. T., McKenna, M. F., Clapp, M., Meyer, E., Stabenau, E., Angeloni, L. M., et al. (2018). Efficacy of Extracting Indices from Large-Scale Acoustic Recordings to Monitor Biodiversity. Conservation Biol. 32 (5), 1174-1184. doi:10.1111/cobi.13119

Colbo, K., Ross, T., Brown, C., and Weber, T. (2014). A Review of Oceanographic Applications of Water Column Data from Multibeam Echosounders. Estuarine Coastal Shelf Sci. 145, 41-56. doi:10.1016/j.ecss.2014.04.002

Collier, J. S., and Brown, C. J. (2005). Correlation of Sidescan Backscatter with Grain Size Distribution of Surficial Seabed Sediments. Mar. Geol. 214 (4), 431-449. doi:10.1016/j.margeo.2004.11.011

Costanza, R., Andrade, F., Antunes, P., den Belt, M. v., Boersma, D., Boesch, D. F., Catarino, F., Hanna, S., Limburg, K., Low, B., Molitor, M., Pereira, J. G., Rayner, S., Santos, R., Wilson, J., and Young, M. (1998). Principles for Sustainable Governance of the Oceans. Science 281 (5374), 198-199. doi:10.1126/ science.281.5374.198

Crossin, G. T., Heupel, M. R., Holbrook, C. M., Hussey, N. E., Lowerre-Barbieri, S. K., Nguyen, V. M., et al. (2017). Acoustic Telemetry and Fisheries Management. Ecol. Appl. 27 (4), 1031-1049. doi:10.1002/eap.1533

Deichmann, J. L., Acevedo-Charry, O., Barclay, L., Burivalova, Z., CamposCerqueira, M., d'Horta, F., et al. (2018). It's Time to Listen: There Is Much to Be Learned from the Sounds of Tropical Ecosystems. Biotropica 50 (5), 713-718. doi:10.1111/btp.12593

Desjonquères, C., Gifford, T., and Linke, S. (2020). Passive Acoustic Monitoring as a Potential Tool to Survey Animal and Ecosystem Processes in Freshwater Environments. Freshw. Biol. 65 (1), 7-19. doi:10.1111/fwb.13356

Dias, F. F., Pedrini, H., and Minghim, R. (2021). Soundscape Segregation Based on Visual Analysis and Discriminating Features. Ecol. Inform. 61, 101184. doi:10.1016/j.ecoinf.2020.101184

Diviacco, P., Nadali, A., Iurcev, M., Burca, M., Carbajales, R., Gangale, M., et al. (2021). Underwater Noise Monitoring with Real-Time and Low-Cost Systems, (The CORMA Experience). JMSE 9 (4), 390. doi:10.3390/jmse9040390

Doser, J. W., Finley, A. O., Kasten, E. P., and Gage, S. H. (2020). Assessing Soundscape Disturbance through Hierarchical Models and Acoustic Indices: A Case Study on a Shelterwood Logged Northern Michigan forest. Ecol. Indicators 113, 106244. doi:10.1016/j.ecolind.2020.106244

Duarte, C. M., Chapuis, L., Collin, S. P., Costa, D. P., Devassy, R. P., Eguiluz, V. M., et al. (2021). The Soundscape of the Anthropocene Ocean. Science 371 (6529), eaba4658. doi:10.1126/science.aba4658

Dubovik, O., Schuster, G. L., Xu, F., Hu, Y., Bösch, H., Landgraf, J., et al. (2021). Grand Challenges in Satellite Remote Sensing. Front. Remote Sens. 2, 619818. doi:10.3389/frsen.2021.619818

Erbe, C., Verma, A., McCauley, R., Gavrilov, A., and Parnum, I. (2015). The marine Soundscape of the Perth Canyon. Prog. Oceanography 137, 38-51. doi:10.1016/ j.pocean.2015.05.015

Fairbrass, A. J., Rennert, P., Williams, C., Titheridge, H., and Jones, K. E. (2017). Biases of Acoustic Indices Measuring Biodiversity in Urban Areas. Ecol. Indicators 83, 169-177. doi:10.1016/j.ecolind.2017.07.064

Fielding, S., Griffiths, G., and Roe, H. S. J. (2004). The Biological Validation of ADCP Acoustic Backscatter through Direct Comparison with Net Samples and Model Predictions Based on Acoustic-Scattering Models. ICES J. Mar. Sci. 61 (2), 184-200. doi:10.1016/j.icesjms.2003.10.011

Foley, J. A., Ramankutty, N., Brauman, K. A., Cassidy, E. S., Gerber, J. S., Johnston, M., et al. (2011). Solutions for a Cultivated Planet. Nature 478 (7369), 337-342. doi:10.1038/nature10452

Foote, K. G. (2009). “Acoustic Methods: Brief Review and Prospects for Advancing Fisheries Research," in The Future of Fisheries Science in North America. Editors R. J. Beamish and B. J. Rothschild (Berlin: Springer), 31, 313-343. doi:10.1007/ 978-1-4020-9210-7_18 
Fuller, S., Axel, A. C., Tucker, D., and Gage, S. H. (2015). Connecting Soundscape to Landscape: Which Acoustic index Best Describes Landscape Configuration? Ecol. Indicators 58, 207-215. doi:10.1016/j.ecolind.2015.05.057

Gaida, T., Tengku Ali, T., Snellen, M., Amiri-Simkooei, A., van Dijk, T., and Simons, D. (2018). A Multispectral Bayesian Classification Method for Increased Acoustic Discrimination of Seabed Sediments Using MultiFrequency Multibeam Backscatter Data. Geosciences 8 (12), 455. doi:10.3390/geosciences8120455

Gartner, J. W. (2004). Estimating Suspended Solids Concentrations from Backscatter Intensity Measured by Acoustic Doppler Current Profiler in San Francisco Bay, California. Mar. Geol. 211 (3-4), 169-187. doi:10.1016/ j.margeo.2004.07.001

Gasc, A., Sueur, J., Jiguet, F., Devictor, V., Grandcolas, P., Burrow, C., et al. (2013a). Assessing Biodiversity with Sound: Do Acoustic Diversity Indices Reflect Phylogenetic and Functional Diversities of Bird Communities? Ecol. Indicators 25, 279-287. doi:10.1016/j.ecolind.2012.10.009

Gasc, A., Sueur, J., Pavoine, S., Pellens, R., and Grandcolas, P. (2013b). Biodiversity Sampling Using a Global Acoustic Approach: Contrasting Sites with Microendemics in New Caledonia. PloS one 8 (5), e65311. doi:10.1371/ journal.pone.0065311

Gottesman, B., Sprague, J., Kushner, D., Bellisario, K., Savage, D., McKenna, M., et al. (2020). Soundscapes Indicate Kelp forest Condition. Mar. Ecol. Prog. Ser. 654, 35-52. doi:10.3354/meps 13512

Gottesman, B. L., Olson, J. C., Yang, S., Acevedo-Charry, O., Francomano, D., Martinez, F. A., et al. (2021). What Does Resilience Sound like? Coral Reef and Dry forest Acoustic Communities Respond Differently to Hurricane Maria. Ecol. Indicators 126, 107635. doi:10.1016/j.ecolind.2021.107635

Grasmueck, M., Eberli, G. P., Viggiano, D. A., Correa, T., Rathwell, G., and Luo, J. (2006). Autonomous Underwater Vehicle (AUV) Mapping Reveals Coral mound Distribution, Morphology, and Oceanography in Deep Water of the Straits of Florida. Geophys. Res. Lett. 33 (23), L23616. doi:10.1029/2006GL027734

Hansen, M. C., and Loveland, T. R. (2012). A Review of Large Area Monitoring of Land Cover Change Using Landsat Data. Remote Sensing Environ. 122, 66-74. doi:10.1016/j.rse.2011.08.024

Hayes, M. P., and Gough, P. T. (2009). Synthetic Aperture Sonar: A Review of Current Status. IEEE J. Oceanic Eng. 34 (3), 207-224. doi:10.1109/JOE.2009.2020853

Huancapaza Hilasaca, L. M., Gaspar, L. P., Ribeiro, M. C., and Minghim, R. (2021). Visualization and Categorization of Ecological Acoustic Events Based on Discriminant Features. Ecol. Indicators 126, 107316. doi:10.1016/ j.ecolind.2020.107316

Hill, A. P., Prince, P., Piña Covarrubias, E., Doncaster, C. P., Snaddon, J. L., and Rogers, A. (2018). AudioMoth: Evaluation of a Smart Open Acoustic Device for Monitoring Biodiversity and the Environment. Methods Ecol. Evol. 9 (5), 1199-1211. doi:10.1111/2041-210x.12955

Ierodiaconou, D., Schimel, A. C. G., Kennedy, D., Monk, J., Gaylard, G., Young, M., et al. (2018). Combining Pixel and Object Based Image Analysis of Ultra-high Resolution Multibeam Bathymetry and Backscatter for Habitat Mapping in Shallow marine Waters. Mar. Geophys. Res. 39 (1-2SI), 271-288. doi:10.1007/ s11001-017-9338-z

Kang, J. (2006). Urban Sound Environment. London: CRC Press.

Kates, R. W., Clark, W. C., Corell, R., Hall, J. M., Jaeger, C. C., Lowe, I., et al. (2001). Sustainability Science. Science 292 (5517), 641-642. doi:10.1126/ science. 1059386

Koh, L. P., Dunn, R. R., Sodhi, N. S., Colwell, R. K., Proctor, H. C., and Smith, V. S. (2004). Species Coextinctions and the Biodiversity Crisis. Science 305 (5690), 1632-1634. doi:10.1126/science.1101101

Lacharité, M., Brown, C. J., and Gazzola, V. (2018). Multisource Multibeam Backscatter Data: Developing a Strategy for the Production of Benthic Habitat Maps Using Semi-automated Seafloor Classification Methods. Mar. Geophys. Res. 39, 307-322. doi:10.1007/s11001-017-9331-6

Lammers, M. O., Brainard, R. E., Au, W. W. L., Mooney, T. A., and Wong, K. B. (2008). An Ecological Acoustic Recorder (EAR) for Long-Term Monitoring of Biological and Anthropogenic Sounds on Coral Reefs and Other marine Habitats. J. Acoust. Soc. Am. 123 (3), 1720-1728. doi: $10.1121 / 1.2836780$

Lecours, V., Dolan, M. F. J., Micallef, A., and Lucieer, V. L. (2016). A Review of marine Geomorphometry, the Quantitative Study of the Seafloor. Hydrol. Earth Syst. Sci. 20 (8), 3207-3244. doi:10.5194/hess-20-3207-2016
Lin, T. H., and Tsao, Y. (2020). Source Separation in Ecoacoustics: A Roadmap towards Versatile Soundscape Information Retrieval. Remote Sens Ecol. Conserv. 6 (3), 236-247. doi:10.1002/rse2.141

Lin, T.-H., Akamatsu, T., Sinniger, F., and Harii, S. (2021). Exploring Coral Reef Biodiversity via Underwater Soundscapes. Biol. Conservation 253, 108901. doi:10.1016/j.biocon.2020.108901

Linke, S., Decker, E., Gifford, T., and Desjonquères, C. (2020). Diurnal Variation in Freshwater Ecoacoustics: Implications for Site-level Sampling Design. Freshw. Biol. 65 (1), 86-95. doi:10.1111/fwb.13227

Lurton, X. (2010). An Introduction to Underwater Acoustics: Principles and Applications. 2nd ed. Berlin, Heidelberg: Springer-Verlag. Available at: https://www.springer.com/gp/book/9783540784807.

Mayer, L., Jakobsson, M., Allen, G., Dorschel, B., Falconer, R., Ferrini, V., et al. (2018). The Nippon Foundation-GEBCO Seabed 2030 Project: The Quest to See the World's Oceans Completely Mapped by 2030. Geosciences 8 (2), 63. doi:10.3390/geosciences8020063

Mayer, L. (2002). 3D Visualization for Pelagic Fisheries Research and Assessment. ICES J. Mar. Sci. 59 (1), 216-225. doi:10.1006/jmsc.2001.1125

Mayer, L. A. (2006). Frontiers in Seafloor Mapping and Visualization. Mar. Geophys. Res. 27 (1), 7-17. doi:10.1007/s11001-005-0267-x

McConnell, D. R., Zhang, Z., and Boswell, R. (2012). Review of Progress in Evaluating Gas Hydrate Drilling Hazards. Mar. Pet. Geol. 34 (1), 209-223. doi:10.1016/j.marpetgeo.2012.02.010

McKenna, M. F., Ross, D., Wiggins, S. M., and Hildebrand, J. A. (2012). Underwater Radiated Noise from Modern Commercial Ships. J. Acoust. Soc. Am. 39-40 (1), 92-103. doi:10.1121/1.3664100

Micallef, A., Le Bas, T. P., Huvenne, V. A. I., Blondel, P., Hühnerbach, V., Deidun, A., et al. (2012). A Multi-Method Approach for Benthic Habitat Mapping of Shallow Coastal Areas with High-Resolution Multibeam Data. Continental Shelf Res. 39-40, 14-26. doi:10.1016/j.csr.2012.03.008

Misiuk, B., Brown, C. J., Robert, K., and Lacharité, M. (2020). Harmonizing MultiSource Sonar Backscatter Datasets for Seabed Mapping Using Bulk Shift Approaches. Remote Sensing 12 (4), 601. doi:10.3390/rs12040601

Mooney, T. A., Di Iorio, L., Lammers, M., Lin, T.-H., Nedelec, S. L., Parsons, M., et al. (2020). Listening Forward: Approaching marine Biodiversity Assessments Using Acoustic Methods. R. Soc. Open Sci. 7 (8), 201287. doi:10.1098/ rsos.201287

Mulla, D. J. (2013). Twenty Five Years of Remote Sensing in Precision Agriculture: Key Advances and Remaining Knowledge Gaps. Biosyst. Eng. 114 (4), 358-371. doi:10.1016/j.biosystemseng.2012.08.009

Muñoz, L., Aspillaga, E., Palmer, M., Saraiva, J. L., and Arechavala-Lopez, P. (2020). Acoustic Telemetry: A Tool to Monitor Fish Swimming Behavior in Sea-Cage Aquaculture. Front. Mar. Sci. 7, 645. doi:10.3389/fmars.2020.00645

Myers, V., and Fawcett, J. (2010). A Template Matching Procedure for Automatic Target Recognition in Synthetic Aperture Sonar Imagery. IEEE Signal. Process. Lett. 17 (7), 683-686. doi:10.1109/LSP.2010.2051574

Orr, J. C., Fabry, V. J., Aumont, O., Bopp, L., Doney, S. C., Feely, R. A., et al. (2005). Anthropogenic Ocean Acidification over the Twenty-First century and its Impact on Calcifying Organisms. Nature 437 (7059), 681-686. doi:10.1038/ nature 04095

Patricelli, G. L., and Blickley, J. L. (2006). Avian Communication in Urban Noise: Causes and Consequences of Vocal Adjustment. Auk 123 (3), 639-649. doi:10.1093/auk/123.3.639

Pekin, B. K., Jung, J., Villanueva-Rivera, L. J., Pijanowski, B. C., and Ahumada, J. A. (2012). Modeling Acoustic Diversity Using Soundscape Recordings and LIDAR-Derived Metrics of Vertical forest Structure in a Neotropical Rainforest. Landscape Ecol. 27 (10), 1513-1522. doi:10.1007/s10980-0129806-4

Pieretti, N., and Farina, A. (2013). Application of a Recently Introduced index for Acoustic Complexity to an Avian Soundscape with Traffic Noise. J. Acoust. Soc. Am. 134 (1), 891-900. doi:10.1121/1.4807812

Pijanowski, B. C., Farina, A., Gage, S. H., Dumyahn, S. L., and Krause, B. L. (2011a). What Is Soundscape Ecology? an Introduction and Overview of an Emerging New Science. Landscape Ecol. 26 (9), 1213-1232. doi:10.1007/s10980-011-9600-8

Pijanowski, B. C., Villanueva-Rivera, L. J., Dumyahn, S. L., Farina, A., Krause, B. L., Napoletano, B. M., et al. (2011b). Soundscape Ecology: the Science of Sound in the Landscape. BioScience 61 (3), 203-216. doi:10.1525/ bio.2011.61.3.6 
Pijanowski, B. C., Rodríguez-Buriticá, S., and Ulloa, J. S. (2021). Tooting the Latin American Horn: Advances in the Scholarship of Ecoacoustics and Soundscape Ecology Is Occurring with Vigor. Biota colombiana 22 (1), 2-6.

Pimm, S. L., Russell, G. J., Gittleman, J. L., and Brooks, T. M. (1995). The Future of Biodiversity. Science 269 (5222), 347-350. doi:10.1126/ science.269.5222.347

Piper, D. J. W., Cochonat, P., and Morrison, M. L. (1999). The Sequence of Events Around the Epicentre of the 1929 Grand Banks Earthquake: Initiation of Debris Flows and Turbidity Current Inferred from Sidescan Sonar. Sedimentology 46 (1), 79-97. doi:10.1046/j.1365-3091.1999.00204.x

Pittman, S., Yates, K., Bouchet, P., Alvarez-Berastegui, D., Andréfouët, S., Bell, S., et al. (2021). Seascape Ecology: Identifying Research Priorities for an Emerging Ocean Sustainability Science. Mar. Ecol. Prog. Ser. 663, 1-29. doi:10.3354/ meps13661

Pittman, S. J. (2017). Seascape Ecology. 1st Edition Oxford. Wiley-Blackwell.

Polyak, L., Edwards, M. H., Coakley, B. J., and Jakobsson, M. (2001). Ice Shelves in the Pleistocene Arctic Ocean Inferred from Glaciogenic Deep-Sea Bedforms. Nature 410 (6827), 453-457. doi:10.1038/35068536

Potamitis, I., Ntalampiras, S., Jahn, O., and Riede, K. (2014). Automatic Bird Sound Detection in Long Real-Field Recordings: Applications and Tools. Appl. Acoust. 80, 1-9. doi:10.1016/j.apacoust.2014.01.001

Rockström, J., Steffen, W., Noone, K., Persson, A., Chapin, F. S., Lambin, E. F., et al. (2009). A Safe Operating Space for Humanity. Nature 461 (7263), 472-475. doi: $10.1038 / 461472 \mathrm{a}$

Roe, P., Eichinski, P., Fuller, R. A., McDonald, P. G., Schwarzkopf, L., Towsey, M., et al. (2021). The Australian Acoustic Observatory. Methods Ecol. Evol. 12, 1802-1808. doi:10.1111/2041-210X.13660

Rountree, R. A., and Juanes, F. (2017). Potential of Passive Acoustic Recording for Monitoring Invasive Species: Freshwater Drum Invasion of the Hudson River via the New York Canal System. Biol. Invasions 19 (7), 2075-2088. doi:10.1007/ s10530-017-1419-z

Rountree, R. A., and Juanes, F. (2020). Potential for Use of Passive Acoustic Monitoring of Piranhas in the Pacaya-Samiria National Reserve in Peru. Freshw. Biol. 65 (1), 55-65. doi:10.1111/fwb.13185

Rountree, R. A., Juanes, F., and Bolgan, M. (2020). Temperate Freshwater Soundscapes: A Cacophony of Undescribed Biological Sounds Now Threatened by Anthropogenic Noise. Plos one 15 (3), e0221842. doi:10.1371/journal.pone.0221842

Roy, D. P., Huang, H., Houborg, R., and Martins, V. S. (2021). A Global Analysis of the Temporal Availability of PlanetScope High Spatial Resolution Multi-Spectral Imagery. Remote Sensing Environ. 264, 112586. doi:10.1016/j.rse.2021.112586

Ruddick, B., Song, H., Dong, C., and Pinheiro, L. (2009). Water Column Seismic Images as Maps of Temperature Gradient. Oceanog. 22 (1), 192-205. doi:10.5670/oceanog.2009.19

Schafer, R. M. (1993). The Soundscape: Our Sonic Environment and the Tuning of the World. Rochester, Vermont Simon \& Schuster.

Servick, K. (2014). Eavesdropping on Ecosystems. Science 343, 834. doi:10.1126/ science.343.6173.834

Sherrit, S., Bao, X., Lee, H. J., Badescu, M., Bar-Cohen, Y., and Malaska, M. (2021). "Acoustic Sensor Network for Planetary Exploration," in Sensors and Smart Structures Technologies for Civil, Mechanical, and Aerospace Systems Bellingham, Washington (International Society for Optics and Photonics), Vol. 11591, 115910N.

Sousa-Lima, R. S., Norris, T. F., Oswald, J. N., and Fernandes, D. P. (2013). A Review and Inventory of Fixed Autonomous Recorders for Passive Acoustic Monitoring of Marine Mammals. Aquat. Mammals 39 (1), 23-53. doi:10.1578/ am.39.1.2013.23

Sueur, J., Aubin, T., and Simonis, C. (2008). Seewave, a Free Modular Tool for Sound Analysis and Synthesis. Bioacoustics 18 (2), 213-226. doi:10.1080/ 09524622.2008.9753600

Thomson, J., Polagye, B., Durgesh, V., and Richmond, M. C. (2012). Measurements of Turbulence at Two Tidal Energy Sites in Puget Sound, WA. IEEE J. Oceanic Eng. 37 (3), 363-374. doi:10.1109/JOE.2012.2191656
Thorsnes, T., Chand, S., Brunstad, H., Lepland, A., and Lågstad, P. (2019). Strategy for Detection and High-Resolution Characterization of Authigenic Carbonate Cold Seep Habitats Using Ships and Autonomous Underwater Vehicles on Glacially Influenced Terrain. Front. Mar. Sci. 6, 708. doi:10.3389/ fmars.2019.00708

Towsey, M., Zhang, L., Cottman-Fields, M., Wimmer, J., Zhang, J., and Roe, P. (2014). Visualization of Long-Duration Acoustic Recordings of the Environment. Proced. Comput. Sci. 29, 703-712. doi:10.1016/ j.procs.2014.05.063

Turner, B. L., Clark, W. C., Kates, R. W., Richards, J. F., Mathews, J. T., and Meyer, W. B. (Editors) (1990). The Earth as Transformed by Human Action: Global and Regional Changes in the Biosphere over the Past 300 Years (CUP Archive) Cambridge University Press, Cambridge and New York.

Villanueva-Rivera, L. J., Pijanowski, B. C., and Villanueva-Rivera, M. L. J. (2018). Package 'soundecology. R. Package Version, 1(3), 3.

Virant-Doberlet, M., Kuhelj, A., Polajnar, J., and Šturm, R. (2019). Predator-prey Interactions and Eavesdropping in Vibrational Communication Networks. Front. Ecol. Evol. 7, 203. doi:10.3389/fevo.2019.00203

Warren, P. S., Katti, M., Ermann, M., and Brazel, A. (2006). Urban Bioacoustics: It's Not Just Noise. Anim. Behav. 71 (3), 491-502. doi:10.1016/ j.anbehav.2005.07.014

Wilson, M. F. J., O'Connell, B., Brown, C., Guinan, J. C., and Grehan, A. J. (2007). Multiscale Terrain Analysis of Multibeam Bathymetry Data for Habitat Mapping on the continental Slope. Mar. Geodesy 30 (1-2), 3-35. doi:10.1080/01490410701295962

Wilson, B. R., Brown, C. J., Sameoto, J. A., Lacharité, M., Redden, A. M., and Gazzola, V. (2021). Mapping Seafloor Habitats in the Bay of Fundy to Assess Megafaunal Assemblages Associated with Modiolus modiolus Beds. Estuarine, Coastal Shelf Sci. 252, 107294. doi:10.1016/j.ecss.2021.107294

Wu, W., Zhan, Z., Peng, S., Ni, S., and Callies, J. (2020). Seismic Ocean Thermometry. Science 369 (6510), 1510-1515. doi:10.1126/science.abb9519

Wu, J. (2013). Landscape Sustainability Science: Ecosystem Services and Human Well-Being in Changing Landscapes. Landscape Ecol. 28 (6), 999-1023. doi:10.1007/s10980-013-9894-9

Wynn, R. B., Huvenne, V. A. I., Le Bas, T. P., Murton, B. J., Connelly, D. P., Bett, B. J., et al. (2014). Autonomous Underwater Vehicles (AUVs): Their Past, Present and Future Contributions to the Advancement of marine Geoscience. Mar. Geology. 352, 451-468. doi:10.1016/ j.margeo.2014.03.012

Yan, L., and Roy, D. P. (2021). Improving Landsat Multispectral Scanner (MSS) Geolocation by Least-Squares-Adjustment Based Time-Series Coregistration. Remote Sensing Environ. 252, 112181. doi:10.1016/ j.rse.2020.112181

Zhao, Z., Zhang, S.-h., Xu, Z.-y., Bellisario, K., Dai, N.-h., Omrani, H., et al. (2017). Automated Bird Acoustic Event Detection and Robust Species Classification. Ecol. Inform. 39, 99-108. doi:10.1016/j.ecoinf.2017.04.003

Conflict of Interest: The authors declare that the research was conducted in the absence of any commercial or financial relationships that could be construed as a potential conflict of interest.

Publisher's Note: All claims expressed in this article are solely those of the authors and do not necessarily represent those of their affiliated organizations, or those of the publisher, the editors and the reviewers. Any product that may be evaluated in this article, or claim that may be made by its manufacturer, is not guaranteed or endorsed by the publisher.

Copyright $\odot 2022$ Pijanowski and Brown. This is an open-access article distributed under the terms of the Creative Commons Attribution License (CC BY). The use, distribution or reproduction in other forums is permitted, provided the original author(s) and the copyright owner(s) are credited and that the original publication in this journal is cited, in accordance with accepted academic practice. No use, distribution or reproduction is permitted which does not comply with these terms. 